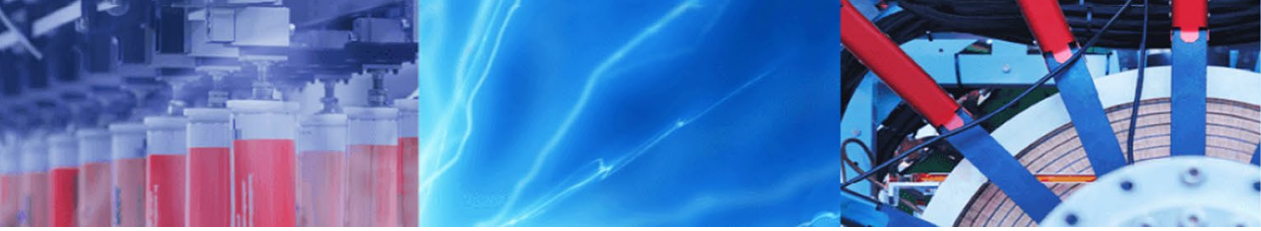

Research Article

\title{
Solvation thermodynamic parameters for sodium dodecyl sulfate (SDS) and sodium lauryl ether sulfate (SLES) surfactants in aqueous and alcoholic-aqueous solvents
}

\author{
Farid I. El-Dossoki ${ }^{1} \cdot$ Esam A. Gomaa ${ }^{2}$ Osama K. Hamza ${ }^{3}$
}

C) Springer Nature Switzerland AG 2019

\begin{abstract}
Conductivity of sodium dodecyl sulfate (SDS) and sodium lauryl ether sulfate (SLES) surfactants in aqueous and in alcoholic-aqueous mixed solvents (methanol, ethanol, and glycerol) with different mole fractions of alcohols has been measured experimentally at different temperatures $(298.15,303.15,308.15$ and $313.15 \mathrm{~K})$. Surface tension was also measured experimentally for SDS and SLES in aqueous solution at $298.15 \mathrm{~K}$. Critical micelle concentration (CMC) of both SDS and SLES was determined from the measured conductivity and surface tension data. The CMC was found to increase as the temperature and alcohol mole fraction increased in all solvents used. Depending on the conductivity data, the association constant $\left(K_{a}\right)$ of both SDS and SLES was also determined applying Shedlowsky conductance equation. The thermodynamic parameters $\left(\Delta G^{\circ}, \Delta H^{\circ}\right.$, and $\left.\Delta S^{\circ}\right)$ of the micellization and association processes were evaluated from the temperature dependence of micellization and association constants. The results indicate that the association constant of both SDS and SLES decrease as the temperature and alcohol mole fraction increased in all solvents used. Also it was found that CMC and $K_{a}$ of both SDS and SLES increase in the order: methanol > ethanol > glycerol. The association process was found to be spontaneous one. The density and refractive index of both SDS and SLES in aqueous and in alcoholicaqueous mixed solvents (methanol, ethanol, and glycerol) with different mole fractions of alcohols, has been measured experimentally at $298.15 \mathrm{~K}$. Depending on the density data, the molar volume of the two surfactants was determined and discussed. Also depending on the refractive index data, the molar refraction and the polarizability of both SDS and SLES was calculated and discussed. A computer programs were used for all calculations.
\end{abstract}

Keywords SDS $\cdot$ SLES $\cdot$ Conductivity $\cdot$ Micellization $\cdot$ Association constant $\cdot$ Molar volume $\cdot$ Refractive index

\section{Introduction}

Many chemical industry, such as oil recovery, oil slick dispersion for environmental protection, detergents, paints, dyestuffs, paper coatings, inks, plastics and fibers, personal care and cosmetics, agrochemicals, pharmaceuticals, food processing, etc. are considered as surfactants applications specially in the system of ionic surfactants in mixed solvents.

At low concentrations, most properties are similar to those of a simple electrolyte.

One notable exception is the surface tension, which decreases rapidly with increasing surfactant concentration. However, all the properties (interfacial and bulk) Electronic supplementary material The online version of this article (https://doi.org/10.1007/s42452-019-0974-6) contains
supplementary material, which is available to authorized users.

Farid I. El-Dossoki, Feldossoki64@gmail.com | ${ }^{1}$ Chemistry Department, Faculty of Science, Port-Said University, Port-Said, Egypt. ${ }^{2}$ Chemistry Department, Faculty of Science, Mansoura University, Mansoura, Egypt. ${ }^{3}$ Egyphar Company for Pharmaceutical Drugs, Cairo, Egypt.

SN Applied Sciences (2019) 1:933 | https://doi.org/10.1007/s42452-019-0974-6

Received: 6 April 2019 / Accepted: 22 July 2019 / Published online: 29 July 2019 
show an abrupt change at a particular concentration, which is consistent with the fact that at and above this concentration, surface active ions or molecules in solution associate to form larger units. These associated units are called micelles (self-assembled structures) and the first formed aggregates are generally approximately spherical.

The concentration at which this association phenomenon occurs is known as the critical micelle concentration (CMC). Each surfactant molecules has a characteristic CMC at a given temperature and electrolyte concentration. The Critical Micelle Concentration indicates the usually narrow range of concentrations separating the limits, at below which most of the surfactant is in the monomeric state and above which virtually all additional surfactants enters the micellar state [1]. The size and shape of the micellization can be controlled by varying surfactant concentration and structure, solvent properties, temperature, $\mathrm{pH}$, and so on. The variation of the $\mathrm{CMC}$ with chemical and physical parameters provides good insights into the nature of the surfactant self-association. The physical methods for CMC determination includes conductivity, solubility, viscosity, light scattering, measuring the surface tension by Wiebelmy slide method or by the method of maximum bubble pressure, measurement of ion activity and by dye incorporation method, Gel filtration spectrophtometrically and counter ion magnetic resonance [2-6]. Some authors had been used the conductivity measurements to study the micellization of; SDS surfactant in water and in propanol-water mixed solvent [7-12], other surfactant [13, 14] and ionic liquids [15-19]. The density measurements had been used to calculate the molar volume of some surfactants [20] and other substances in different solutions [21-24]. The refractive index measurements had been used to study the solvation of some substances in different solutions [25-27]. The effect of the solvent, temperature degree and the chemical nature of the surfactants on the different solvation thermodynamic properties of both SDS and SLES were of little interest in the literatures in the point of view of the CMC, molal volume, association constant and polarizability measurements.

Based on the above introduction, the present work aims to study the solvation thermodynamic parameters (CMC, association constants, molal volume and the polarizability) of both SDS and SLES using different measurements such as; conductivity, surface tension, density, and refractive index in aqueous and in different mole fractions of alcoholic (methanol, ethanol, and glycerol)-aqueous solvents at different temperatures $(298.15,303.15,308.15$ and $313.15 \mathrm{~K})$.

\section{Experimental}

\subsection{Chemicals and solutions}

\begin{tabular}{|c|c|c|c|c|c|}
\hline $\begin{array}{l}\text { Compo- } \\
\text { nent }\end{array}$ & & $\begin{array}{l}\text { Suppli- } \\
\text { ers }\end{array}$ & $\begin{array}{l}\% \text { Purity } \\
\text { before } \\
\text { purifica- } \\
\text { tion }\end{array}$ & $\begin{array}{l}\text { Purifi- } \\
\text { cation } \\
\text { method }\end{array}$ & $\begin{array}{l}\% \text { Purity } \\
\text { before } \\
\text { purifica- } \\
\text { tion }\end{array}$ \\
\hline $\begin{array}{l}\text { Sodium } \\
\text { dode- } \\
\text { cyl } \\
\text { sulfate } \\
\text { (SDS) }\end{array}$ & Scheme 1 & $\begin{array}{l}\text { Sigma } \\
\text { Aldrich }\end{array}$ & $(99.0)$ & \multirow{5}{*}{$\begin{array}{l}\text { The com- } \\
\text { ponents } \\
\text { were } \\
\text { used } \\
\text { without } \\
\text { further } \\
\text { purifica- } \\
\text { tion }\end{array}$} & (99.0) \\
\hline $\begin{array}{l}\text { Sodium } \\
\text { lauryl } \\
\text { ether } \\
\text { sulfate } \\
\text { (SLES) }\end{array}$ & Scheme 2 & $\begin{array}{l}\text { Royal } \\
\text { Chemi- } \\
\text { cals }\end{array}$ & $(98.0)$ & & $(98.0)$ \\
\hline Ethanol & & $\begin{array}{l}\text { Sigma } \\
\text { Aldrich }\end{array}$ & (99.8) & & (99.8) \\
\hline $\begin{array}{l}\text { Metha- } \\
\text { nol }\end{array}$ & & $\begin{array}{l}\text { Sigma } \\
\text { Aldrich }\end{array}$ & (99.9) & & (99.9) \\
\hline Glycerol & & $\begin{array}{l}\text { Sigma } \\
\text { Aldrich }\end{array}$ & $(\geq 99.0)$ & & $(\geq 99.0)$ \\
\hline
\end{tabular}

All solutions were prepared in cleaned glass volumetric flasks. Bidistilled water with conductivity between 0.05 and $0.5 \mu \mathrm{S} \mathrm{cm}^{-1}$ was used to prepare the required Stock solutions. Stock solution $\left(0.1 \mathrm{~mol} \mathrm{~L}^{-1}\right)$ and $\left(0.01 \mathrm{~mol} \mathrm{~L}^{-1}\right)$ of both SDS and SLES surfactant, respectively, was prepared.

\subsection{Apparatus and procedure}

The conductivity measurements were carried out using a Jenway Conductivity Bridge of certainty $\left( \pm 0.025 \mu \mathrm{S} \mathrm{cm}^{-1}\right)$. The conductivity bridge was calibrated by the determination of the cell constant, $K_{\text {cell }}$, using different standard potassium chloride solutions [28]. The conductivity was measured as a function of both SDS and SLES concentration. To avoid dilution error in the preparation of different SDS and SLES surfactant solutions, the concentration of the sample

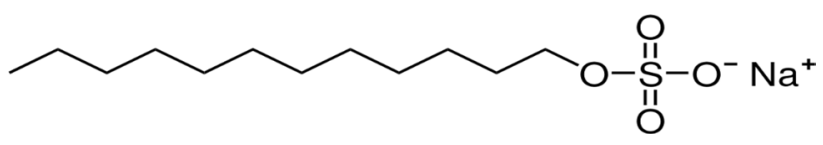

Scheme 1 Sodium dodecyl sulfate (SDS)

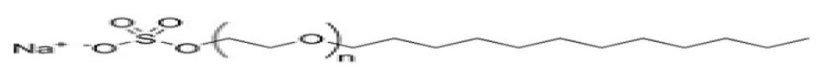

Scheme 2 Sodium lauryl ether sulfate (SLES) 
solution was successively increased by a stepwise addition of 0.25 or $0.5 \mathrm{~mL}$ of the previously prepared surfactant solution $\left(0.1 \mathrm{~mol} \mathrm{~L}^{-1}\right)$ and $\left(0.01 \mathrm{~mol} \mathrm{~L}^{-1}\right)$ to $40.0 \mathrm{~mL}$ of pure solvent initially placed in a double jacket glass cell. The temperature of the solution in the double jacket glass cell was kept constant within $\pm 0.1 \mathrm{~K}$ of a desired temperature using an ultrathermostate of type (MLW 3230, Germany). After each addition, the solution was stirred to ensure homogeneous mixing, and then was subjected to the conductivity measurement. The uncertainty in the conductivity measurement is $\pm 0.025 \mu \mathrm{S} \mathrm{cm}^{-1}$. The specific conductance was measured in duplicate and an average of the measurements was then used for calculations. The Surface tension measurements were carried out using a digital tensiometer K9 (ring method).

\section{Results and discussion}

\subsection{Concentration dependence of conductivity}

The conductivity of both SDS and SLES surfactants in aqueous and in alcoholic-aqueous mixed solvents (methanol, ethanol, and glycerol) with different mole fractions of alcohols, has been measured experimentally at different temperatures $(298.15,303.15,308.15$ and $313.15 \mathrm{~K})$ as described in the experimental section. To estimate the CMC of SDS and SLES in different solutions and at different temperatures, the relation of the measured conductivity versus the surfactants concentration was done as presented in Figs. 1, 2, 3, 4, 5, 6, 7, 8 and (S1-S12). The CMC for both SDS and SLES was also estimated at $298.15 \mathrm{~K}$ in water solvent using the surface tension measurements as presented in Figs. 9 and 10. The CMC values of both SDS and SLES in aqueous and in alcoholic-aqueous mixed solvents
Fig. 1 Conductivity as a function of concentration for SDS in water at different temperatures
Fig. 2 Conductivity as a function of concentration for SDS in ethanol-water mixture with ethanol mole fraction 0.0331 at different temperatures
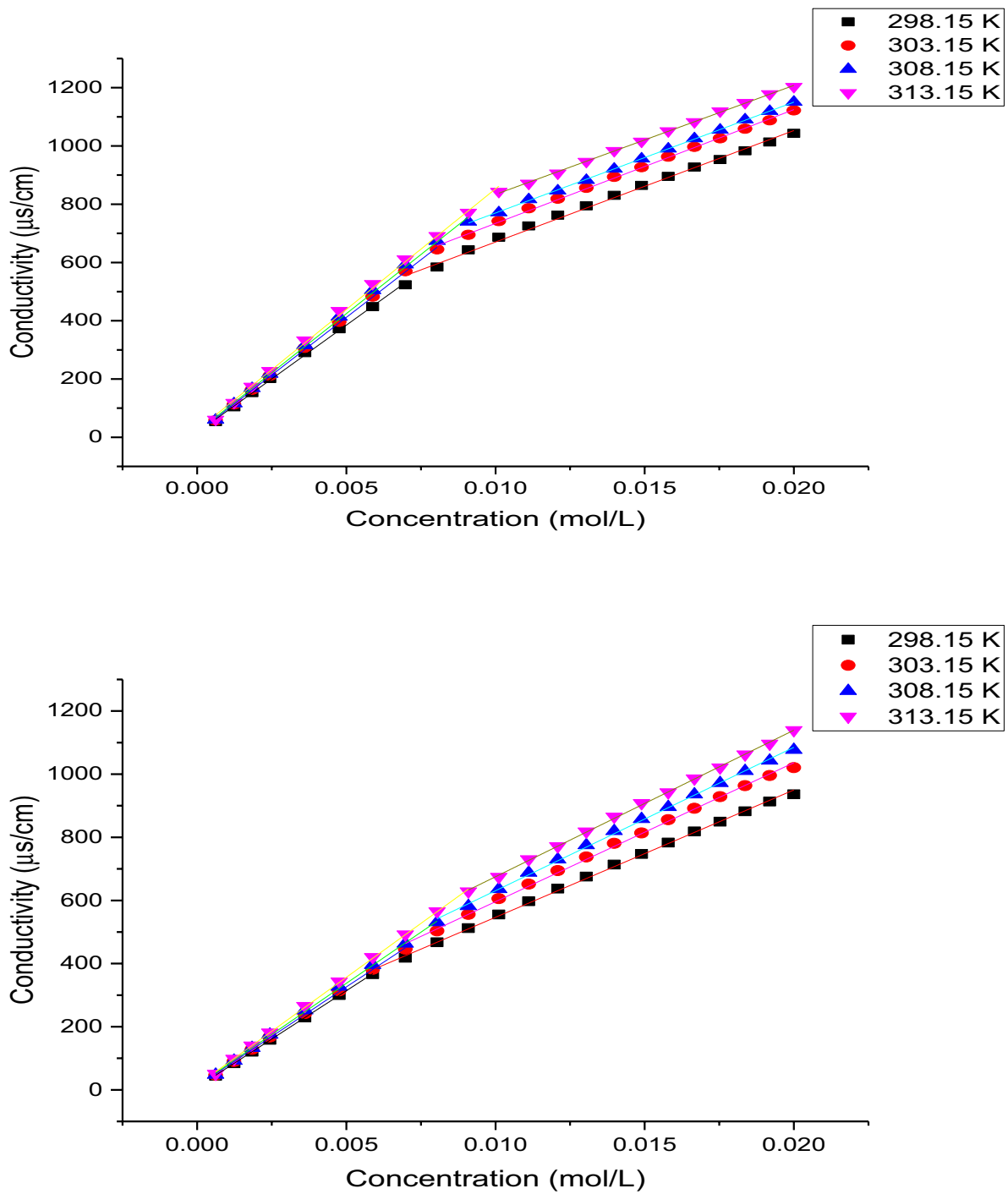

SN Applied Sciences a SPRINGER NATURE journal 

tion of concentration for SDS in methanol mole fraction 0.0470 at different temperatures
Fig. 3 Conductivity as a funcmethanol-water mixture with

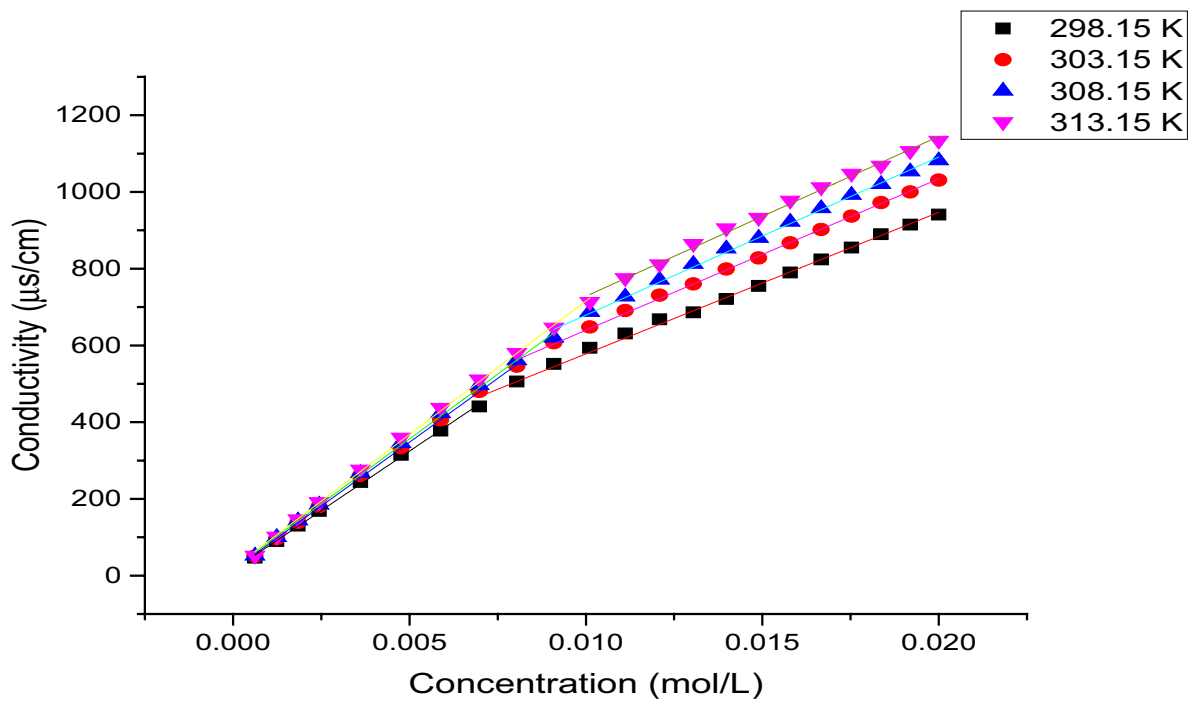

Fig. 4 Conductivity as a function of concentration for SDS in glycerol-water mixture with glycerol mole fraction 0.0267 at different temperatures

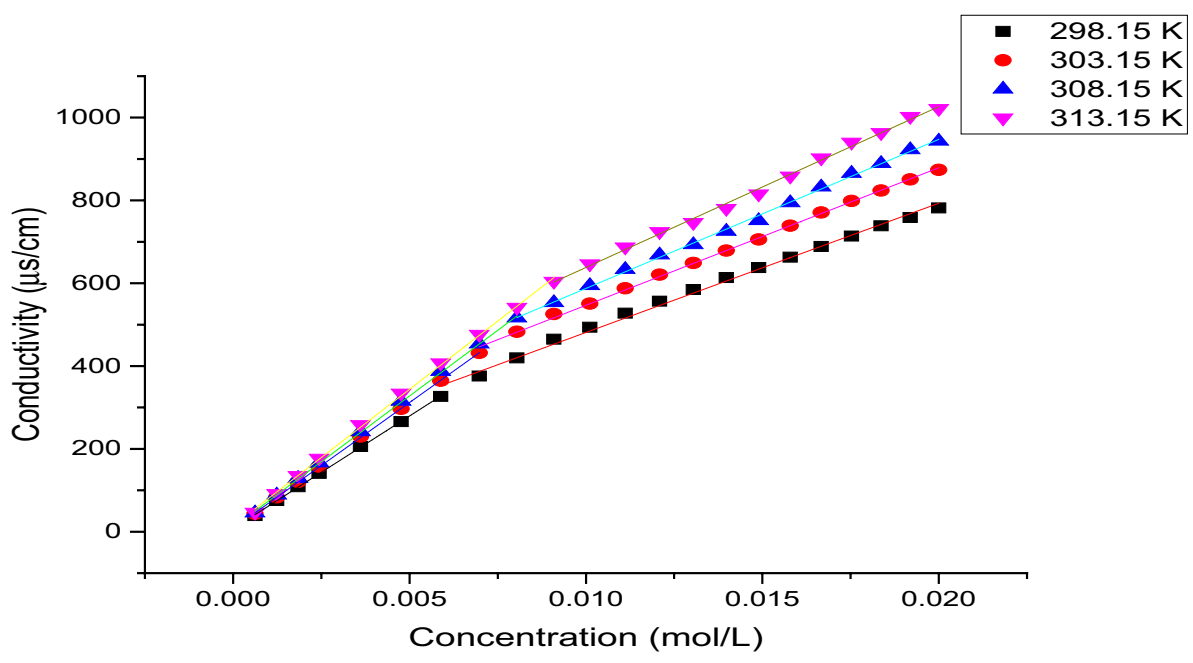

(methanol, ethanol, and glycerol) with different mole fractions of alcohols, at different temperatures $(298.15,303.15$, 308.15 and $313.15 \mathrm{~K}$ ) are collected in Tables 1 and 2. The CMC values of SDS and SLES from the literature are presented in Tables 1 and 2 in parentheses.

The CMC of both SDS and SLES was found to increase as the temperature and alcohol mole fraction increased in all solvents used (Figs. 11, 12 as example). This may be related to the more solvation (less micellization) of both SDS and SLES as the temperature and alcohol mole fraction increased as a result of the dissociation of the interand intra-hydrogen bonds.

Also it was found that CMC of the two surfactants increase in the order: methanol-water > ethanol-water > glycerol-water. This may be as a result of the higher viscosity in the reverse order; methanol-water < ethanol-water < glycerol-water and lower dipole moments in the same order; methanol-water $>$ ethanol-water $>$ glycerol-water. The higher is the viscosity and the lower is the dipole moment, the lower the solvation of both SDS and SLES and then low micellization, then low CMC. The CMC of both SDS and SLES in water at $298 \mathrm{~K}$ was found to agree with literature value $[29,42]$. This can be also related to the effect of the hydrogen bond perturbation in this mixed solvent systems which differs from glycerol-water to that of ethanol-water and methanol-water.

In comparing the CMC values of the surfactants under study, it was found that CMC of the SDS surfactant is more than that of SLES surfactant. This may be related to the presence of ether group in SLES, which may decrease the solvation (increase the micellization) of SLES than that of SDS as a result of hydrogen bond formation.

The degree of ionization in the micelle $(a)$ and the degree of counter ion binding, $\beta=(1-a)$ of both (SDS) and (SLES) as a function of mole fraction of alcohol at different 
Fig. 5 Conductivity as a function of concentration for SLES in water at different temperatures

Fig. 6 Conductivity as a function of concentration for SLES in ethanol-water mixture with ethanol mole fraction 0.0331 at different temperatures
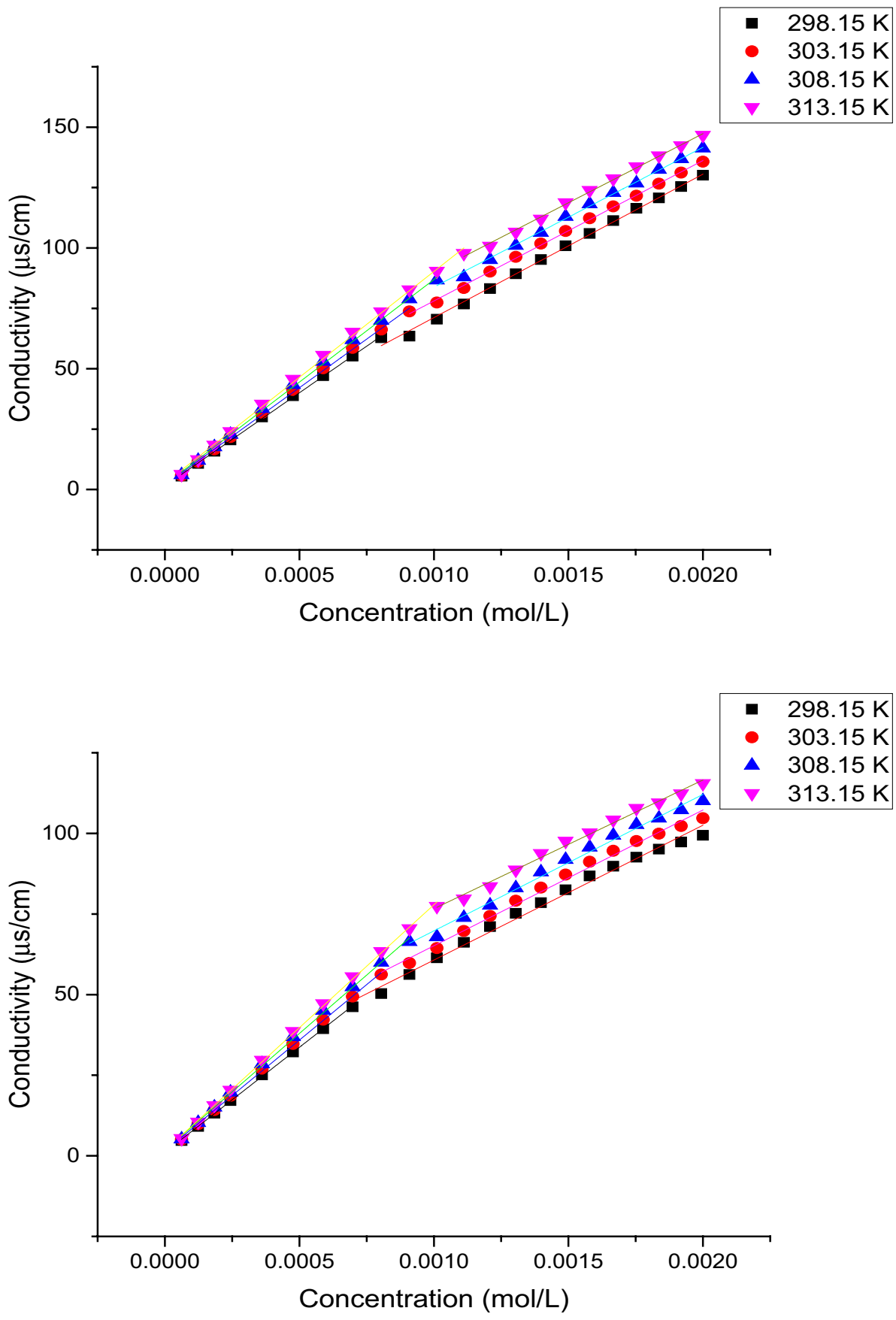

temperatures were calculated as in the following equation [5]:

$\alpha=S_{2} / S_{1}$

where $S_{2} / S_{1}$, the ratio of slopes of post and pre micelle regions and subsequently $\beta$ was calculated as, $(\beta=1-\alpha)$. The slopes were estimated from the linear plots of conductivity versus the concentration of surfactants. The values of $\alpha$ and $\beta$ are recorded in Tables 3 and 4 .

The thermodynamic parameters of micellization were obtained using the following equations:
$\Delta G_{\text {mic }}=(2-\alpha) R T \ln [\mathrm{CMC}]$

$\Delta G_{\text {mic }}=\Delta H_{\text {mic }}-T \Delta S_{\text {mic }}$

where $a$ is the degree of ionization in the micelle, $R$ is the gas constant and $T$ is the absolute temperature. The standard free energy change $\left(\Delta G_{\text {mic }}\right)$, the standard enthalpy change $\left(\Delta H_{\text {mic }}\right)$ and the standard entropy change $\left(\Delta S_{\text {mic }}\right)$ of micellization process of both SDS and SLES were calculated by plotting of $\left(\Delta G_{\text {mic }}\right)$ versus $T$, where the slope $=\left(-\Delta S_{\text {mic }}\right)$ and the intercept $=\left(\Delta H_{\text {mic }}\right)$. 
Fig. 7 Conductivity as a function of concentration for SLES in methanol-water mixture with methanol mole fraction 0.0470 at different temperatures
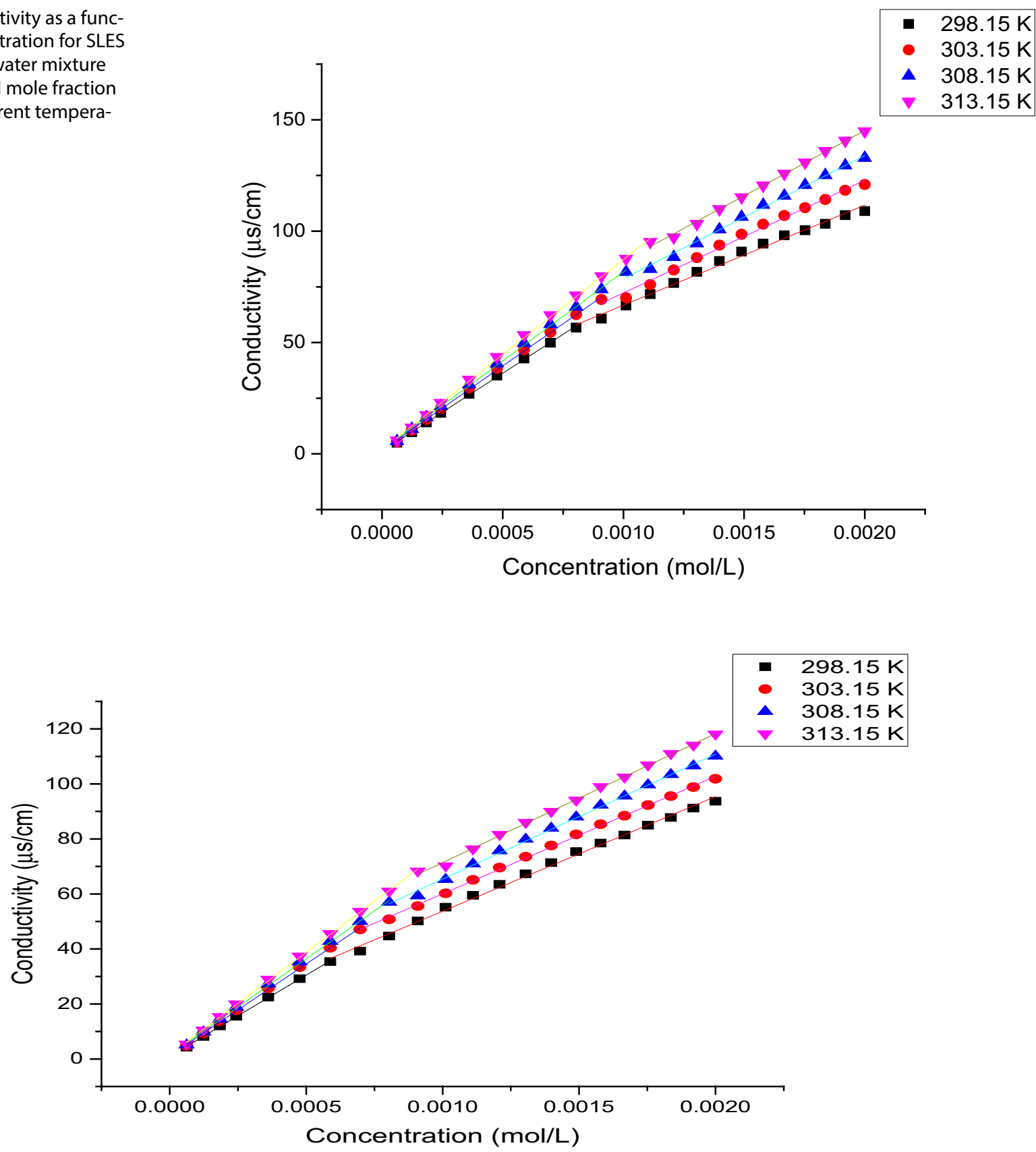

Fig. 8 Conductivity as a function of concentration for SLES in glycerol-water mixture with glycerol mole fraction 0.0267 at different temperatures

Since the conductance of an ion depends on its mobility, it is quite reasonable to treat the rate process taking into account change of temperature on the basis of the following equation:

[CMC] $=A e^{-E a / R T}$

The activation energy of micellization process of both (SDS) and (SLES) can be estimated by plotting of (In CMC) versus $(1 / T)$ where the slope $=\left(-E_{a} / R\right)$ and the intercept $=(\ln A)$. The free energy change $\left(\Delta G_{\text {mic }}\right)$, the enthalpy change $\left(\Delta H_{\text {mic }}\right)$, the entropy change $\left(\Delta S_{\text {mic }}\right)$ and the activation energy of micellization process of (SDS) and (SLES) are presented in Tables 5 and 6.

From Tables 5 and 6 , the values of $\Delta G_{\text {mic }}$ were found to be negative in all cases under study, showing the spontaneity of the micellization process, indicating that the increase in the concentration of alcohols makes the process more spontaneous. Similarly negative values of 


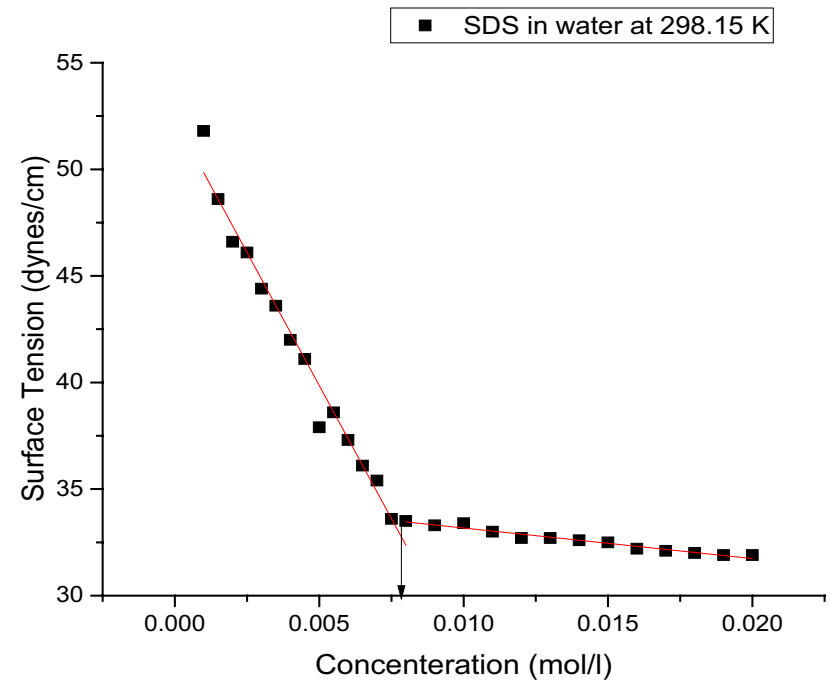

Fig. 9 Surface tension as a function of concentration for SDS in water $298.15 \mathrm{~K}$

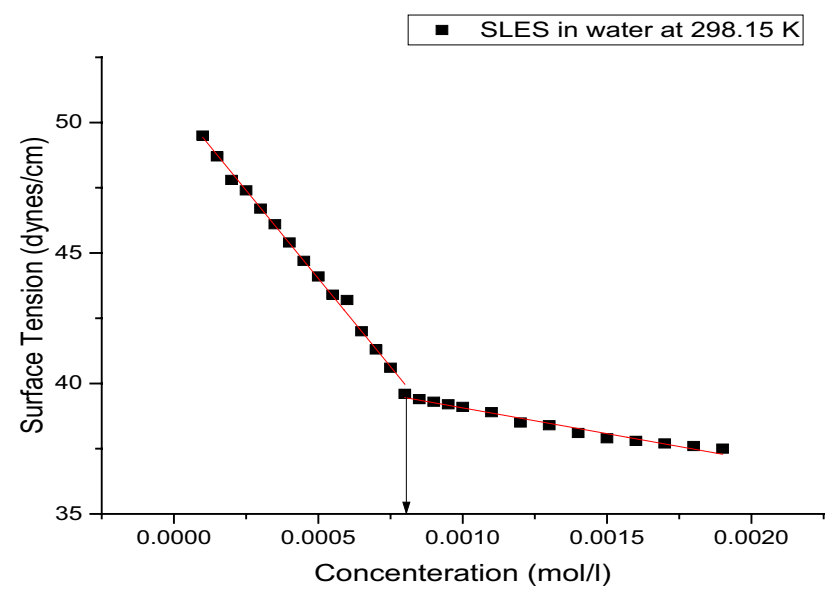

Fig. 10 Surface tension as a function of concentration for SLES in water $298.15 \mathrm{~K}$

$\Delta H_{\text {mic }}$ indicate the exothermic nature of the micellization process. The values of $\Delta S_{\text {mic }}$ were negative which indicate the spontaneity of the micellization process.

\subsection{Association constant and Walden product}

The equivalent conductance $(\Lambda)$ of both SDS and SLES in aqueous and in alcoholic-aqueous mixed solvents (methanol, ethanol, and glycerol) with different mole fractions of alcohols at different temperatures $(298.15,303.15,308.15$ and $313.15 \mathrm{~K}$ ) has been calculated from the measured conductivity before the $\mathrm{CMC}$ applying the following equation:

$\Lambda=1000 \kappa / C$
Table 1 CMC (mol/L) values for SDS in aqueous and in alcoholaqueous mixed solvents at different temperatures

\begin{tabular}{|c|c|c|c|c|c|}
\hline \multirow[t]{2}{*}{ Solvent } & \multirow{2}{*}{$\begin{array}{l}\text { Alcohol } \\
\text { mole frac- } \\
\text { tion }\end{array}$} & \multicolumn{4}{|l|}{$T, K$} \\
\hline & & 298.15 & 303.15 & 308.15 & 313.15 \\
\hline \multirow[t]{4}{*}{ Ethanol-aqueous } & 0.0000 & $\begin{array}{l}0.0080 \\
(0.0080)^{*} \\
\mathbf{0 . 0 0 7 9}\end{array}$ & 0.0089 & 0.0096 & 0.0104 \\
\hline & 0.0331 & 0.0075 & 0.0081 & 0.0087 & 0.0107 \\
\hline & 0.0715 & 0.0080 & 0.0091 & 0.0102 & 0.0115 \\
\hline & 0.1166 & 0.0086 & 0.0098 & 0.0106 & 0.0112 \\
\hline \multirow{4}{*}{$\begin{array}{l}\text { Methanol-aque- } \\
\text { ous }\end{array}$} & 0.0000 & 0.0080 & 0.0089 & 0.0096 & 0.0104 \\
\hline & 0.0470 & 0.0081 & 0.0091 & 0.0102 & 0.0112 \\
\hline & 0.0999 & 0.0096 & 0.0101 & 0.0111 & 0.0121 \\
\hline & 0.1598 & 0.0162 & 0.0112 & 0.0121 & 0.0131 \\
\hline \multirow{4}{*}{$\begin{array}{l}\text { Glycerol-aque- } \\
\text { ous }\end{array}$} & 0.0000 & 0.0080 & 0.0089 & 0.0096 & 0.0104 \\
\hline & 0.0267 & 0.0071 & 0.0075 & 0.0081 & 0.0096 \\
\hline & 0.0582 & 0.0081 & 0.0091 & 0.0097 & 0.0106 \\
\hline & 0.0958 & 0.0091 & 0.0096 & 0.0105 & 0.0113 \\
\hline
\end{tabular}

*The values in parentheses are from [29] while values in bold italic are from surface tension measurements

The limiting equivalent conductance, $\Lambda_{\circ}$ of SDS and SLES were determined from the intercept of the Onsager relation [30] of $\Lambda$ versus $C^{1 / 2}$ in the following equation:

$\Lambda=\Lambda_{\circ}-B C^{1 / 2}$

The experimental data for conductivity measurements were analyzed using Shedlowsky extrapolation equation [31], to get the association constant of the SDS and SLES, which follows equation:

$\frac{1}{\Lambda S(z)}=\frac{1}{\Lambda_{\circ}}+\frac{K_{a} C \Lambda S(z) \gamma_{i}^{2}}{\Lambda_{\circ}^{2}}$

$S(z)$ is the Shedlowsky function, which can be calculated as follow:

$z=A \frac{\sqrt{C \Lambda}}{\Lambda_{\circ}^{3 / 2}}$

$S(z)=\left\{\frac{Z}{2}+\sqrt{1+(Z / 2)^{2}}\right\}^{2}$

$A$ is the Onsager coefficient $=8.2 \times 10^{5 \Lambda_{0}} /(\varepsilon T)^{3 / 2}+\left(82 / \eta_{0}\right)$ $(\varepsilon T)^{1 / 2}$ where $\varepsilon$ is the relative permittivity, $\eta_{0}$ is the viscosity of the solvent and $T$ is the absolute temperature. $\gamma_{i}$ is the mean activity coefficient estimated from the Debye-Huckel limiting law as modified by Robinson and Stokes. Using the data of $(\Lambda), S(z)$ and $\left(\Lambda_{0}\right)$, the value of degree of both SDS and SLES ionization (a) was calculated applying the following equation: 
Table 2 CMC ( $\mathrm{mol} / \mathrm{L})$ values for SLES in aqueous and in alcohol- aqueous mixed solvents at different temperatures

\begin{tabular}{llllll}
\hline Solvent & $\begin{array}{l}\text { Alcohol mole } \\
\text { fraction }\end{array}$ & \multicolumn{1}{l}{$T, K$} & & & \\
\cline { 3 - 5 } & & 298.15 & 303.15 & 308.15 & 313.15 \\
\hline Ethanol-aqueous & 0.0000 & $\begin{array}{l}0.00079 \\
(0.00077)^{* *}\end{array}$ & 0.00092 & 0.00101 & 0.00107 \\
& & & & \\
& 0.0080 & & & \\
Methanol-aqueous & 0.00070 & 0.00081 & 0.00091 & 0.00110 \\
& 0.0715 & 0.00091 & 0.00100 & 0.00111 & 0.00121 \\
& 0.1166 & 0.00101 & 0.00111 & 0.00121 & 0.00131 \\
& 0.0000 & 0.00079 & 0.00092 & 0.00101 & 0.00107 \\
Glycerol-aqueous & 0.0470 & 0.00081 & 0.00091 & 0.00102 & 0.00111 \\
& 0.0999 & 0.00091 & 0.00101 & 0.00112 & 0.00121 \\
& 0.1598 & 0.00101 & 0.00111 & 0.00121 & 0.00131 \\
& 0.0000 & 0.00079 & 0.00092 & 0.00101 & 0.00107 \\
& 0.0267 & 0.00048 & 0.00069 & 0.00080 & 0.00092 \\
& 0.0582 & 0.00070 & 0.00081 & 0.00091 & 0.00101 \\
& 0.0958 & 0.00080 & 0.00091 & 0.00101 & 0.00112 \\
\hline
\end{tabular}

**The values in parentheses are from [42] while values in bold italic are from surface tension measurements

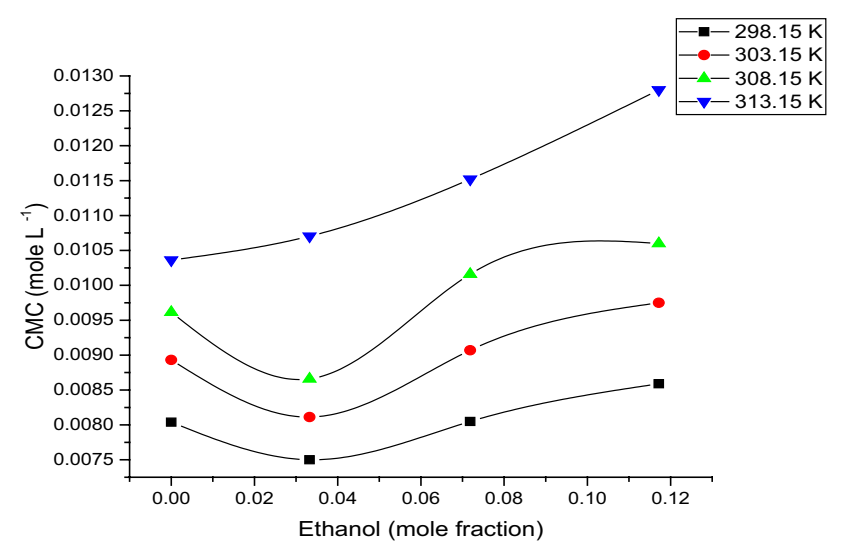

Fig. 11 CMC for SDS as a function of mole fraction of ethanol at different temperatures

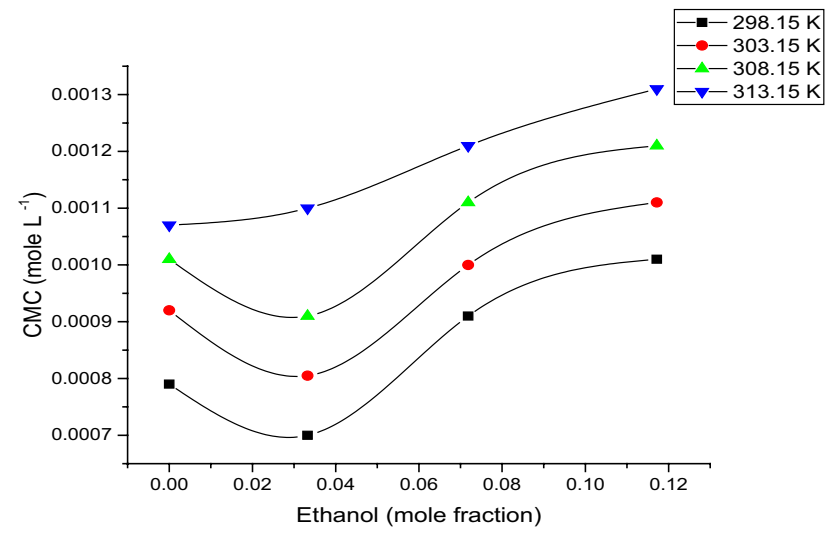

Fig. 12 CMC for SLES as a function of mole fraction of ethanol at different temperatures

\section{SN Applied Sciences}

$\alpha=\Lambda S(z) / \Lambda^{\circ}$

Using $(\alpha)$ and $(\varepsilon)$ values, the mean activity coefficients $\left(\gamma_{ \pm}\right)$was evaluated applying the following equation:

$\log \gamma_{ \pm}=-\left(Z_{+} Z_{-} A C^{1 / 2}\right) /\left(1-B r C^{1 / 2}\right)$

where $Z-, Z+$ are the charges of ions in solutions, $A, B$ are the Debye-Hückel constant and $(r)$ is the solvated radius.

$A=1.82410^{6} /(\varepsilon T)^{3 / 2} ; \quad B=50.2910^{8}(\varepsilon T)^{-1 / 2}$

The values of the triple ion association constant $\left(K_{3}\right)$ were calculated [32] applying the following equation:

$\frac{\Lambda \sqrt{c}}{\sqrt{\left(1-\frac{\Lambda}{\Lambda_{\circ}}\right)}}=\frac{\Lambda_{\circ}}{\sqrt{K_{a}}}+\frac{C \lambda_{3}^{\circ}}{K_{3} \sqrt{K_{a}}}\left(1-\frac{\Lambda}{\Lambda_{\circ}}\right)$

Equation 12 was derived by Fuoss and using Walden approximation $\left(\Lambda_{\circ}=3 \lambda_{0}\right)$. The value of $K_{3}$ was calculated and was found to be very small values $(-0.00006$ to -0.00029 ) indicating no chance for the triple ion association.

The values of the standard free energy change of association $\left(\Delta G_{a}\right)$ were calculated applying the following equation:

$\Delta G_{a}=-2.303 R T \log K_{a}$

where $R$ is the gas constant and $T$ is the absolute temperature. The standard enthalpy change $\left(\Delta H_{a}\right)$ and the standard entropy change $\left(\Delta S_{a}\right)$ of association process of SDS 
Table 3 The degree of ionization $(a)$ and the degree of counter ion binding, $\beta=(1-\alpha)$ of SDS as a function of mole fraction of alcohol at different temperatures

\begin{tabular}{|c|c|c|c|c|c|c|c|c|c|}
\hline \multirow[t]{2}{*}{ Solvent } & \multirow{2}{*}{$\begin{array}{l}\text { Alcohol } \\
\text { mole frac- } \\
\text { tion }\end{array}$} & \multicolumn{4}{|l|}{$a$} & \multicolumn{4}{|c|}{$\beta=(1-\alpha)$} \\
\hline & & 298.15 & 303.15 & 308.15 & 313.15 & 298.15 & 303.15 & 308.15 & 313.15 \\
\hline \multirow[t]{4}{*}{ Ethanol-aqueous } & 0.0000 & 0.527 & 0.500 & 0.494 & 0.528 & 0.473 & 0.500 & 0.506 & 0.472 \\
\hline & 0.0331 & 0.670 & 0.713 & 0.700 & 0.679 & 0.330 & 0.287 & 0.300 & 0.321 \\
\hline & 0.0715 & 0.675 & 0.796 & 0.833 & 0.706 & 0.325 & 0.204 & 0.167 & 0.294 \\
\hline & 0.1166 & 0.800 & 0.885 & 0.804 & 0.835 & 0.200 & 0.115 & 0.196 & 0.165 \\
\hline \multirow[t]{4}{*}{ Methanol-aqueous } & 0.0000 & 0.527 & 0.500 & 0.494 & 0.528 & 0.473 & 0.500 & 0.506 & 0.472 \\
\hline & 0.0470 & 0.582 & 0.589 & 0.600 & 0.607 & 0.418 & 0.411 & 0.400 & 0.393 \\
\hline & 0.0999 & 0.697 & 0.706 & 0.713 & 0.707 & 0.303 & 0.294 & 0.287 & 0.293 \\
\hline & 0.1598 & 0.824 & 0.745 & 0.676 & 0.566 & 0.176 & 0.255 & 0.324 & 0.434 \\
\hline \multirow[t]{4}{*}{ Glycerol-aqueous } & 0.0000 & 0.527 & 0.500 & 0.494 & 0.528 & 0.473 & 0.500 & 0.506 & 0.472 \\
\hline & 0.0267 & 0.585 & 0.556 & 0.569 & 0.604 & 0.415 & 0.444 & 0.431 & 0.396 \\
\hline & 0.0582 & 0.570 & 0.575 & 0.550 & 0.491 & 0.430 & 0.425 & 0.450 & 0.509 \\
\hline & 0.0958 & 0.575 & 0.559 & 0.528 & 0.530 & 0.425 & 0.441 & 0.472 & 0.470 \\
\hline
\end{tabular}

Table 4 The degree of ionization $(a)$ and the degree of counter ion binding, $\beta=(1-a)$ of SLES as a function of mole fraction of alcohol at different temperatures

Table 5 Thermodynamic parameters for micellization of (SDS) in aqueous and in alcohol-aqueous mixed solvents

\begin{tabular}{|c|c|c|c|c|c|c|c|c|c|}
\hline \multirow[t]{2}{*}{ Solvent } & \multirow{2}{*}{$\begin{array}{l}\text { Alcohol } \\
\text { mole frac- } \\
\text { tion }\end{array}$} & \multicolumn{4}{|l|}{$a$} & \multicolumn{4}{|c|}{$\beta=(1-a)$} \\
\hline & & 298.15 & 303.15 & 308.15 & 313.15 & 298.15 & 303.15 & 308.15 & 313.15 \\
\hline \multirow[t]{4}{*}{ Ethanol-aqueous } & 0.0000 & 0.770 & 0.722 & 0.682 & 0.727 & 0.230 & 0.278 & 0.318 & 0.273 \\
\hline & 0.0331 & 0.642 & 0.612 & 0.584 & 0.545 & 0.358 & 0.388 & 0.416 & 0.455 \\
\hline & 0.0715 & 0.686 & 0.664 & 0.664 & 0.622 & 0.314 & 0.336 & 0.336 & 0.378 \\
\hline & 0.1166 & 0.642 & 0.640 & 0.621 & 0.616 & 0.358 & 0.360 & 0.379 & 0.384 \\
\hline \multirow[t]{4}{*}{ Methanol-aqueous } & 0.0000 & 0.770 & 0.722 & 0.682 & 0.727 & 0.230 & 0.278 & 0.318 & 0.273 \\
\hline & 0.0470 & 0.643 & 0.669 & 0.692 & 0.687 & 0.357 & 0.331 & 0.308 & 0.313 \\
\hline & 0.0999 & 0.707 & 0.717 & 0.689 & 0.661 & 0.293 & 0.283 & 0.311 & 0.339 \\
\hline & 0.1598 & 0.671 & 0.636 & 0.626 & 0.590 & 0.329 & 0.364 & 0.374 & 0.410 \\
\hline \multirow[t]{4}{*}{ Glycerol-aqueous } & 0.0000 & 0.770 & 0.722 & 0.682 & 0.727 & 0.230 & 0.278 & 0.318 & 0.273 \\
\hline & 0.0267 & 0.605 & 0.641 & 0.650 & 0.632 & 0.395 & 0.359 & 0.350 & 0.368 \\
\hline & 0.0582 & 0.587 & 0.581 & 0.575 & 0.557 & 0.413 & 0.419 & 0.425 & 0.443 \\
\hline & 0.0958 & 0.518 & 0.488 & 0.483 & 0.434 & 0.482 & 0.512 & 0.517 & 0.566 \\
\hline
\end{tabular}

\begin{tabular}{|c|c|c|c|c|c|c|c|c|}
\hline \multirow[t]{3}{*}{ Solvent } & \multirow{3}{*}{$\begin{array}{l}\text { Alcohol } \\
\text { mole frac- } \\
\text { tion }\end{array}$} & \multicolumn{4}{|l|}{$\Delta G_{\text {mic }}$} & \multirow{3}{*}{$\begin{array}{l}\Delta H_{\text {mic }} \\
\mathrm{kJ} / \mathrm{mol}\end{array}$} & \multirow{3}{*}{$\begin{array}{l}\Delta S_{\text {mic }} \\
\mathrm{J} / \mathrm{mol} \mathrm{K}\end{array}$} & \multirow{3}{*}{$\begin{array}{l}E_{a \text { mic }} \\
\mathrm{kJ} / \mathrm{mol}\end{array}$} \\
\hline & & \multicolumn{4}{|l|}{$\mathrm{kJ} / \mathrm{mol}$} & & & \\
\hline & & 298.15 & 303.15 & 308.15 & 313.15 & & & \\
\hline \multirow[t]{4}{*}{ Ethanol-aqueous } & 0.0000 & -17.61 & -17.84 & -17.92 & -17.51 & -27.75 & -0.032 & 12.97 \\
\hline & 0.0331 & -16.13 & -15.62 & -15.81 & -15.60 & -26.59 & -0.035 & 17.51 \\
\hline & 0.0715 & -15.83 & -14.27 & -13.72 & -15.03 & -31.76 & -0.053 & 18.46 \\
\hline & 0.1166 & -14.15 & -13.01 & -13.93 & -13.63 & -23.88 & -0.033 & 13.61 \\
\hline \multirow[t]{4}{*}{ Methanol-aqueous } & 0.0000 & -17.61 & -17.84 & -17.92 & -17.51 & -27.75 & -0.032 & 12.97 \\
\hline & 0.0470 & -16.93 & -16.70 & -16.46 & -16.30 & -29.56 & -0.042 & 16.59 \\
\hline & 0.0999 & -15.03 & -14.98 & -14.83 & -14.88 & -18.62 & -0.012 & 12.35 \\
\hline & 0.1598 & -12.02 & -14.21 & -14.98 & -16.19 & 66.81 & 0.265 & 12.50 \\
\hline \multirow[t]{4}{*}{ Glycerol-aqueous } & 0.0000 & -17.61 & -17.84 & -17.92 & -17.51 & -27.75 & -0.032 & 12.97 \\
\hline & 0.0267 & -17.35 & -17.81 & -17.65 & -16.88 & -46.24 & -0.093 & 15.27 \\
\hline & 0.0582 & -17.06 & -16.86 & -17.23 & -17.85 & -0.56 & 0.055 & 13.44 \\
\hline & 0.0958 & -16.58 & -16.88 & -17.18 & -17.16 & -4.53 & 0.041 & 11.30 \\
\hline
\end{tabular}


Table 6 Thermodynamic parameters for micellization of (SLES) in aqueous and in alcohol- aqueous mixed solvents

\begin{tabular}{|c|c|c|c|c|c|c|c|c|}
\hline \multirow[t]{3}{*}{ Solvent } & \multirow{3}{*}{$\begin{array}{l}\text { Alcohol mole } \\
\text { fraction }\end{array}$} & \multicolumn{4}{|l|}{$\Delta G_{\text {mic }}$} & \multirow{3}{*}{$\begin{array}{l}\Delta H_{\text {mic }} \\
\mathrm{kJ} / \mathrm{mol}\end{array}$} & \multirow{3}{*}{$\begin{array}{l}\Delta S_{\text {mic }} \\
\mathrm{J} / \mathrm{mol} \mathrm{K}\end{array}$} & \multirow{3}{*}{$\begin{array}{l}E_{a \text { mic }} \\
\mathrm{kJ} / \mathrm{mo}\end{array}$} \\
\hline & & \multicolumn{4}{|l|}{$\mathrm{kJ} / \mathrm{mol}$} & & & \\
\hline & & 298.15 & 303.15 & 308.15 & 313.15 & & & \\
\hline \multirow[t]{4}{*}{ Ethanol-aqueous } & 0.0000 & -21.78 & -22.51 & -23.30 & -22.67 & -6.09 & 0.053 & 15.62 \\
\hline & 0.0331 & -24.45 & -24.93 & -25.40 & -25.80 & 2.26 & 0.091 & 22.93 \\
\hline & 0.0715 & -22.81 & -23.25 & -23.29 & -24.10 & 0.05 & 0.078 & 14.89 \\
\hline & 0.1166 & -23.22 & -23.32 & -23.73 & -23.91 & -8.33 & 0.050 & 13.46 \\
\hline \multirow[t]{4}{*}{ Methanol-aqueous } & 0.0000 & -21.78 & -22.51 & -23.30 & -22.67 & -6.09 & 0.053 & 15.62 \\
\hline & 0.0470 & -23.94 & -23.49 & -23.09 & -23.26 & -38.29 & -0.049 & 16.40 \\
\hline & 0.0999 & -22.44 & -22.30 & -22.83 & -23.41 & -1.70 & 0.069 & 14.89 \\
\hline & 0.1598 & -22.72 & -23.39 & -23.65 & -24.37 & 8.26 & 0.104 & 13.46 \\
\hline \multirow[t]{4}{*}{ Glycerol-aqueous } & 0.0000 & -21.78 & -22.51 & -23.30 & -22.67 & -6.09 & 0.053 & 15.62 \\
\hline & 0.0267 & -26.42 & -24.93 & -24.65 & -24.89 & -55.00 & -0.097 & 32.71 \\
\hline & 0.0582 & -25.44 & -25.45 & -25.56 & -25.92 & -16.14 & 0.031 & 18.90 \\
\hline & 0.0958 & -26.20 & -26.68 & -26.81 & -27.70 & 1.28 & 0.092 & 17.30 \\
\hline
\end{tabular}

were calculated by plotting of $\left(\Delta G_{a}\right)$ versus $T$, where the slope $=\left(-\Delta S_{a}\right)$ and the intercept $=\left(\Delta H_{a}\right)$.

Since the conductance of an ion depends on its mobility, it is quite reasonable to treat the rate process taking into account the change of temperature on the basis of the following equation:

$\Lambda_{\circ}=A e^{-E a / R T}$

where $A$ is the frequency factor, $R$ is the gas constant and $\mathrm{Ea}$ is Arrhenius activation energy of transfer processes. From the plot of In $\Lambda_{0}$ versus I/T, the Ea values have been calculated from the slope [33].

The values of the association constant and the different thermodynamic parameters of association process of SDS and SLES in aqueous and in alcoholic-aqueous mixed solvents (methanol, ethanol, and glycerol) with different mole fractions of alcohols, at different temperatures (298.15, $303.15,308.15$ and $313.15 \mathrm{~K}$ ), are presented in Tables 7 and 8 , respectively.

The results show that the association constant of both SDS and SLES surfactant decrease as the temperature increased in all solvents used (Figs. 13, 14), respectively. This is reverse to the effect of temperature on the CMC value. This indicates that as the temperature increase, the solvation increase, the association decrease, the micellization decrease and then $C M C$ value increase. The association constant of the two surfactants was also found to firstly increase then decrease as the mole fraction of alcohols increased which reverse the expected change. The first increase in the association constant may be related to decrease in the dielectric constant of alcohols than that of water, as expected from previous studies [15-19, 30, 31]. As the mole fraction of alcohol increases more, the association constant then decrease as reverse to expected from previous studies [15-19, $30,31]$ which may be related to difference between the electrolytic nature of the salts previously studied [15-19, $30,31]$, and the salts under study (SDS). As the alcohol mole fraction increase, the solvation of the hydrocarbon tail of both SDS and SLES increases, and so, the ion-pair association of positive and negative ions in both SDS and SLES molecule decreases.

Also it was found that $K_{a}$ increase in the order: methanol > ethanol > glycerol. This may be related to the higher dielectric constant and the lower dipole moment of glycerol than that both of methanol and ethanol. The association process was found to be spontaneous one as indicated from the negative value of the free energy change. Also, the association process is exothermic one as indicated from the negative value of the enthalpy change.

Also it was found that the $K_{a}$ of the SDS surfactant is lower than that of SLES surfactant. This may be related to the presence of ether group in SLES, which may decrease the solvation (increase the association) of SLES than that of SDS as a result of hydrogen bond formation.

Inspection of the obtained data for the CMC, $a, \beta$ and $K_{a^{\prime}}$ we can note that, as the association constant $\left(K_{a}\right)$ decrease (which related to the conductivity values before CMC, i.e., $S_{1}$ decrease) the degree of ionization in the micelle $(a)$ (which equal $\left.\left(S_{2} / S_{1}\right)\right)$ will, respectively, increase. The counter ion value $(\beta)$ will then decrease as a result of decrease in association constant. From Figs. 11, 13, 12 and 14, it was found as the association constant increase, the CMC decrease. This can be explained whereas the association between the positive and negative charges of the SDS and SLES salt increase, the solvation and so the CMC decrease. 

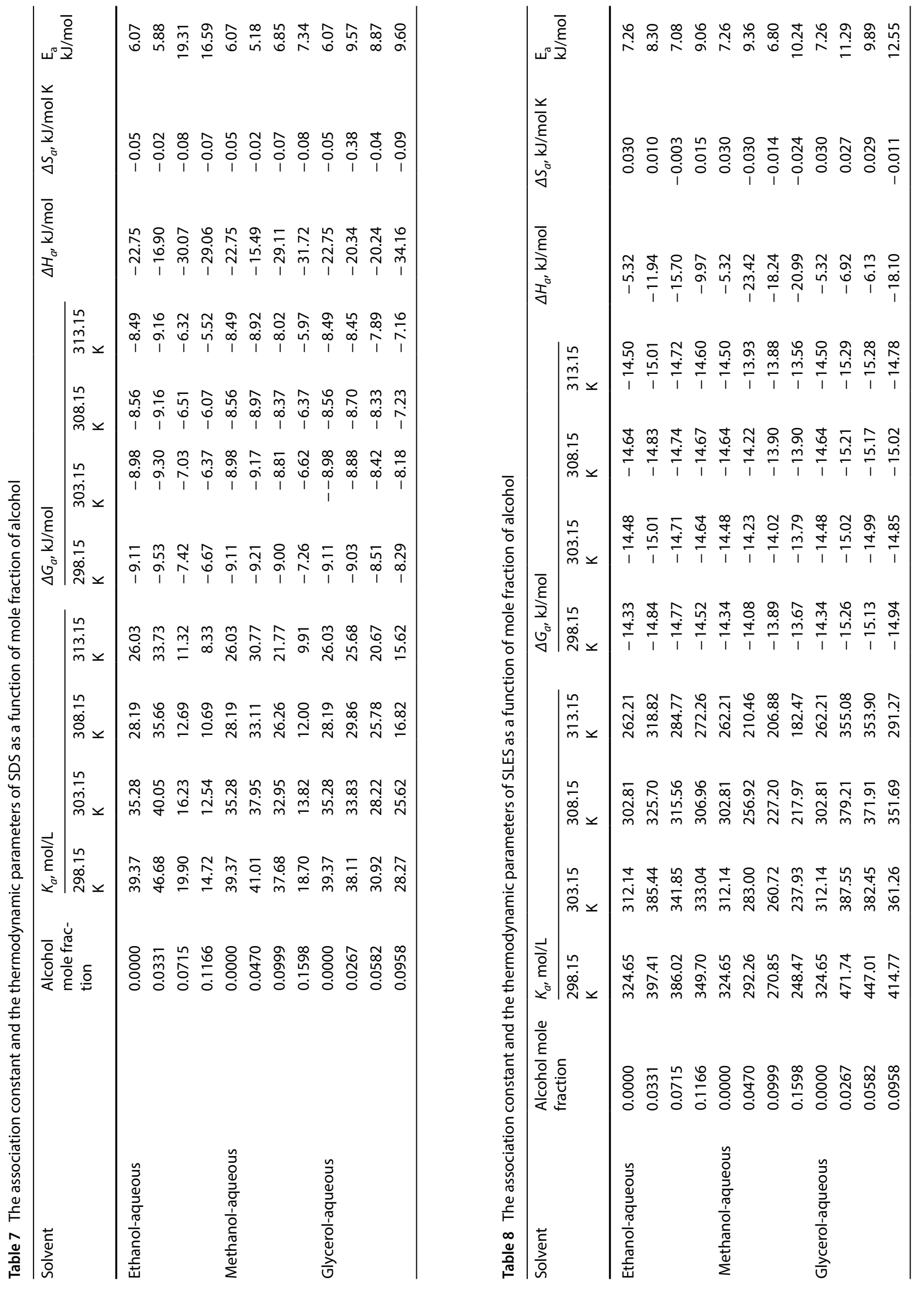
Fig. 13 Association constant $\left(K_{a}\right)$ of SDS as a function of mole fraction ethanol in aqueous solutions at different temperatures

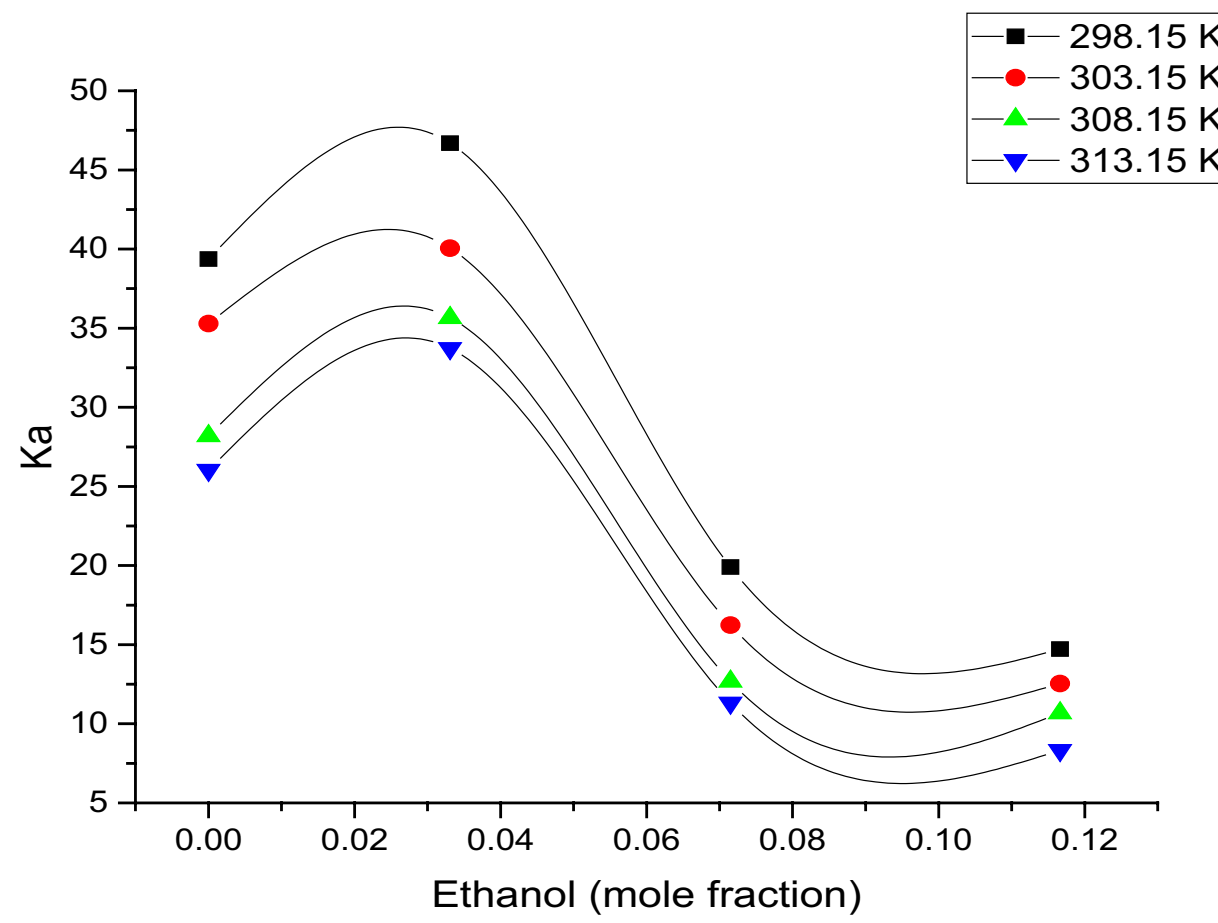

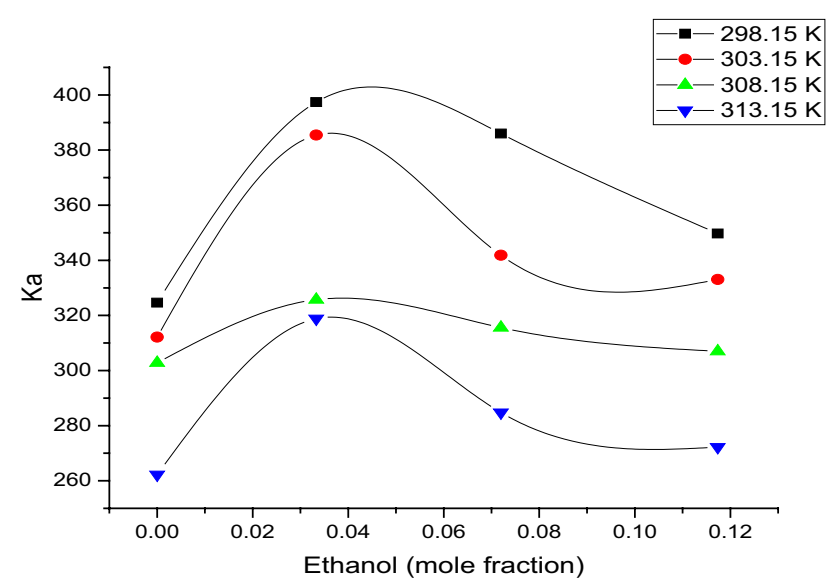

Fig. 14 Association constant $\left(K_{a}\right)$ of SLES as a function of mole fraction ethanol in aqueous solutions at different temperatures

The Walden product $\left(\Lambda_{\circ} \eta_{\circ}\right)$ which are informative from the point of view of ion-solvent interaction [34], has constant value because the molar conductance of an ion at infinite dilution depends only upon its speed and hence, the product of ion conductance by the viscosity of the medium should be independent of the solvent nature. Hence, the Walden product $\left(\Lambda_{\circ} \eta_{\circ}\right)$ is expected to be constant for a given electrolyte in a series of solvent mixtures in which the ion -solvent interactions are uniform.

The Walden product $\left(\Lambda_{\circ} \eta_{\circ}\right)$ values were calculated for both SDS and SLES in aqueous and in alcoholic-aqueous mixed solvents (ethanol, methanol and glycerol) with
Table 9 Walden product $\left(\Lambda_{\circ} \eta_{0}\right)$ of SDS as a function of mole fraction of alcohol at different temperatures

\begin{tabular}{llllll}
\hline Solvent & $\begin{array}{l}\text { Alcohol } \\
\text { mole frac- } \\
\text { tion }\end{array}$ & $\begin{array}{l}\Lambda_{\circ} \eta_{\circ} \\
\mathrm{S} \mathrm{cm}^{2} \mathrm{~mol}^{-1} \mathrm{cP}\end{array}$ \\
\cline { 2 - 6 } & & 298.15 & 303.15 & 308.15 & 313.15 \\
\hline Ethanol-aqueous & 0.0000 & 0.820 & 0.778 & 0.718 & 0.676 \\
& 0.0333 & 0.983 & 0.902 & 0.807 & 1.102 \\
& 0.0720 & 0.931 & 0.980 & 0.906 & 1.357 \\
Methanol-aqueous & 0.1174 & 1.015 & 0.980 & 0.905 & 1.405 \\
& 0.0000 & 0.820 & 0.778 & 0.718 & 0.676 \\
& 0.0472 & 0.592 & 0.630 & 0.640 & 0.658 \\
Glycerol-aqueous & 0.1003 & 0.557 & 0.591 & 0.607 & 0.640 \\
& 0.1604 & 0.497 & 0.538 & 0.555 & 0.576 \\
& 0.0000 & 0.820 & 0.778 & 0.718 & 0.676 \\
& 0.0135 & 0.757 & 0.833 & 0.875 & 0.914 \\
& 0.0298 & 0.797 & 0.856 & 0.894 & 0.950 \\
& 0.0501 & 0.819 & 0.897 & 0.942 & 0.990 \\
\hline
\end{tabular}

different mole fractions of alcohols, at different temperatures $(298.15,303.15,308.15$ and $313.15 \mathrm{~K})$ and their values are presented in Tables 9 and 10. The fluidity ratio $(R x)$ which is the ratio between the values of the Walden product of the two surfactants in alcohol-water solvent to that in water can be calculated.

The Walden product $\left(\Lambda_{\circ} \eta_{\circ}\right)$ of both SDS and SLES solutions was found to increase as alcohol mole fraction increased in the case of ethanol-water and glycerol-water solvent, while it decrease with increase the alcohol mole 
Table 10 Walden product $\left(\Lambda_{\circ} \eta_{\circ}\right)$ of SLES as a function of mole fraction of alcohol at different temperatures

\begin{tabular}{|c|c|c|c|c|c|}
\hline \multirow[t]{3}{*}{ Solvent } & \multirow{3}{*}{$\begin{array}{l}\text { Alcohol } \\
\text { mole frac- } \\
\text { tion }\end{array}$} & \multicolumn{4}{|l|}{$\Lambda_{\diamond} \eta$} \\
\hline & & \multicolumn{4}{|c|}{$\mathrm{Scm}^{2} \mathrm{~mol}^{-1} \mathrm{cP}$} \\
\hline & & 298.15 & 303.15 & 308.15 & 313.15 \\
\hline \multirow[t]{4}{*}{ Ethanol-aqueous } & 0.0000 & 0.831 & 0.780 & 0.738 & 0.697 \\
\hline & 0.0333 & 1.045 & 0.987 & 0.889 & 1.231 \\
\hline & 0.0720 & 1.329 & 1.252 & 1.079 & 1.527 \\
\hline & 0.1174 & 1.470 & 1.392 & 1.213 & 1.764 \\
\hline \multirow[t]{4}{*}{ Methanol-aqueous } & 0.0000 & 0.831 & 0.780 & 0.738 & 0.697 \\
\hline & 0.0472 & 0.622 & 0.678 & 0.712 & 0.748 \\
\hline & 0.1003 & 0.611 & 0.636 & 0.661 & 0.698 \\
\hline & 0.1604 & 0.511 & 0.548 & 0.580 & 0.625 \\
\hline \multirow[t]{4}{*}{ Glycerol-aqueous } & 0.0000 & 0.831 & 0.780 & 0.738 & 0.697 \\
\hline & 0.0135 & 0.837 & 0.934 & 0.987 & 1.046 \\
\hline & 0.0298 & 0.923 & 0.973 & 1.037 & 1.118 \\
\hline & 0.0501 & 0.887 & 0.960 & 1.030 & 1.135 \\
\hline
\end{tabular}

fraction in the case of methanol-water solvent. This can be related to the higher viscosity of ethanol and glycerol than that of water. On the other hand the viscosity of methanol is lower than that of water. The value of the limiting molar conductance $\Lambda_{\circ}$ is decrease as the mole fraction of alcohol (ethanol, methanol and glycerol) increase. This indicates that the effective factor in the change of Walden product is the viscosity of solvent not the limiting molar conductance.

\subsection{Molal volumes}

The density of different molal concentrations of both (SDS) and (SLES) surfactants in aqueous and in alcoholic-aqueous mixed solvents (methanol, ethanol, and glycerol) with different mole fractions of alcohols, has been measured experimentally at $298.15 \mathrm{~K}$. From the molal concentration and the density values, the apparent molal volumes, $V_{\varphi}$ of both SDS and (SLES) in aqueous and in alcoholic-aqueous mixed solvents (ethanol, methanol, and glycerol) with different mole fractions of alcohols, at $298.15 \mathrm{~K}$, were calculated using the following equation [35]:

$V \varphi=\frac{M}{\rho}-\frac{1000}{m}\left[\frac{1}{\rho^{\circ}}-\frac{1}{\rho}\right]$

Where $M$ is the molecular weight of SDS or (SLES), $m$ is the molal concentration of SDS or (SLES) in solution, $\rho$ and $\rho^{\circ}$ are the densities of solution and solvent, respectively. The calculated apparent molal volumes, $V_{\varphi}$ of both SDS and SLES in alcoholic-aqueous mixed solvents (ethanol, methanol, and glycerol) with different alcohol mole fractions at $298.15 \mathrm{~K}$, are given in Tables 11 and 12 .

The packing density (the relation between the Van der Waals volume and the partial molal volume of relatively large molecules is found to be constant [36, 37]). Therefore, it is possible to calculate the Van der Waals volumes $\left(V_{w}\right)$ of the surfactants under study by apply the following equation [37].

Packing density $(P)=V_{w} / V \varphi=0.661 \pm 0.017$
Table 11 Apparent molal volume $\left(V_{\varphi}\right)$, Van der Waals volume $\left(V_{w}\right)$ and electrostriction volume $\left(V_{E}\right)$, of SDS as a function of mole fraction of alcohol at $298.15 \mathrm{~K}$

\begin{tabular}{llllll}
\hline Solvent & $\begin{array}{l}\text { Alcohol mole } \\
\text { fraction }\end{array}$ & $\begin{array}{l}\rho \\
\mathrm{g} \mathrm{cm}^{-3}\end{array}$ & $\begin{array}{l}V_{\varphi} \\
\left(\mathrm{cm}^{3} / \mathrm{mole}\right)\end{array}$ & $\begin{array}{l}V_{W} \\
\left(\mathrm{~cm}^{3} / \mathrm{mole}\right)\end{array}$ & $\begin{array}{l}V_{E} \\
\left(\mathrm{~cm}^{3} / \mathrm{mole}\right)\end{array}$ \\
\hline Ethanol-aqueous & 0.0000 & 1.0682 & 269.8669 & 178.3820 & -91.4849 \\
& 0.0331 & 0.9997 & 288.3645 & 190.6089 & -97.7556 \\
& 0.0715 & 0.9858 & 292.4305 & 193.2966 & -99.1339 \\
& 0.1166 & 0.9699 & 297.2245 & 196.4654 & -100.7591 \\
& 0.2355 & 0.9444 & 305.2545 & 201.7732 & -103.4813 \\
Methanol-aqueous & 0.4182 & 0.9309 & 309.6770 & 204.6965 & -104.9805 \\
& 0.0000 & 1.0682 & 269.8669 & 178.3820 & -91.4849 \\
& 0.0470 & 1.0066 & 286.3871 & 189.3018 & -97.0852 \\
& 0.0999 & 0.9988 & 288.6227 & 190.7796 & -97.8431 \\
& 0.1598 & 0.9846 & 292.7851 & 193.5309 & -99.2541 \\
& 0.3074 & 0.9647 & 298.8225 & 197.5217 & -101.3008 \\
& 0.5088 & 0.9362 & 307.9270 & 203.5397 & -104.3872 \\
& 0.0000 & 1.0682 & 269.8669 & 178.3820 & -91.4849 \\
& 0.0267 & 1.1116 & 259.3282 & 171.4159 & -87.9123 \\
& 0.0582 & 1.1360 & 253.7582 & 167.7341 & -86.0240 \\
& 0.0958 & 1.1610 & 248.2940 & 164.1224 & -84.1717 \\
& 0.1981 & 1.2103 & 238.1806 & 157.4374 & -80.7432 \\
& 0.3657 & 1.2597 & 228.8408 & 151.2638 & -77.5770 \\
\hline
\end{tabular}


Table 12 Apparent molal volume $\left(V_{\varphi}\right)$, Van der Waals volume $\left(V_{W}\right)$ and electrostriction volume $\left(V_{E}\right)$, of SLES as a function of mole fraction of alcohol at $298.15 \mathrm{~K}$

\begin{tabular}{llllll}
\hline Solvent & $\begin{array}{l}\text { Alcohol mole } \\
\text { fraction }\end{array}$ & $\begin{array}{l}\rho \\
\mathrm{g} \mathrm{cm}^{-3}\end{array}$ & $V_{\varphi}\left(\mathrm{cm}^{3} / \mathrm{mole}\right)$ & $\begin{array}{l}V_{W} \\
\left(\mathrm{~cm}^{3} / \mathrm{mole}\right)\end{array}$ & $\begin{array}{l}V_{E} \\
\left(\mathrm{~cm}^{3} / \mathrm{mole}\right)\end{array}$ \\
\hline Ethanol-aqueous & 0.0000 & 1.0050 & 382.0895 & 252.5611 & -129.5283 \\
& 0.0331 & 0.9861 & 389.4128 & 257.4018 & -132.0109 \\
& 0.0715 & 0.9728 & 394.7368 & 260.9210 & -133.8158 \\
& 0.1166 & 0.9600 & 399.9999 & 264.3999 & -135.6000 \\
& 0.2355 & 0.9291 & 413.3030 & 273.1933 & -140.1097 \\
Methanol-aqueous & 0.4182 & 0.9194 & 417.6630 & 276.0752 & -141.5878 \\
& 0.0000 & 1.0050 & 382.0895 & 252.5611 & -129.5283 \\
& 0.0470 & 0.9991 & 384.3457 & 254.0525 & -130.2932 \\
& 0.0999 & 0.9906 & 387.6436 & 256.2324 & -131.4112 \\
& 0.1598 & 0.9762 & 393.3617 & 260.0121 & -133.3496 \\
& 0.3074 & 0.9487 & 404.7640 & 267.5490 & -137.2150 \\
& 0.5088 & 0.9234 & 415.8538 & 274.8793 & -140.9744 \\
& 0.0000 & 1.0050 & 382.0895 & 252.5611 & -129.5283 \\
& 0.0267 & 1.0293 & 373.0811 & 246.6066 & -126.4745 \\
& 0.0582 & 1.0572 & 363.2349 & 240.0983 & -123.1366 \\
& 0.0958 & 1.0990 & 349.4189 & 230.9659 & -118.4530 \\
& 0.1981 & 1.1560 & 332.1710 & 219.5650 & -112.6060 \\
& 0.3657 & 1.2180 & 315.2732 & 208.3956 & -106.8776 \\
\hline
\end{tabular}

The electrostriction volume $\left(V_{e}\right)$ which is the volume compressed by the solvent [36-39], can be calculated using the following equation.

$V_{e}=V_{w}-V \varphi$

The values of the solvated radius, Van Der Waal volume and the electrostriction volume are reported in Tables 11, 12.

The densities values of both SDS and SLES solutions was found to decrease as the alcohol mole fraction increased in case of ethanol-water and methanol-water, while in case of glycerol-water solvents it increase with increasing the alcohol mole fraction. Also it was found that $V_{\varphi}$ of both SDS and SLES solutions increase with increasing the alcohol mole fraction in case of ethanol-water and methanol-water, but it decrease with increasing the alcohol mole fraction glycerol-water. This can related to the value of the density of the alcoholic and aqueous solvents under study (glycerol has more density than water, methanol and ethanol).This may also related to the inter- and intra-hydrogen bonds formed in solution.

\subsection{Refractive index, molar refraction and polarizability}

The refractive indices of both SDS and SLES in aqueous and in alcoholic-aqueous mixed solvents (ethanol, methanol, and glycerol) with different alcohol mole fractions were measured at $298.15 \mathrm{~K}$, and their values are reported in Tables 13 and 14. The refractive indices of both SDS
Table 13 The refractive index $\left(n_{D}\right)$, the atomic polarization $\left(A_{p}\right)$, the molar refraction $\left(R_{m}\right)$ and the polarizability $(a)$ of SDS as a function of mole fraction of alcohol at $298.15 \mathrm{~K}$

\begin{tabular}{|c|c|c|c|c|c|}
\hline Solvent mixtures & $\begin{array}{l}\text { Alcohol } \\
\text { mole frac- } \\
\text { tion }\end{array}$ & $n_{D}$ & $A_{P}$ & $\begin{array}{l}R_{m} \\
\mathrm{~cm}^{3} / \mathrm{mol}\end{array}$ & $\begin{array}{l}a \\
\mathrm{~cm}^{3}\end{array}$ \\
\hline \multirow[t]{6}{*}{ Ethanol-aqueous } & 0.0000 & 1.3385 & 1.8812 & 56.3411 & 2.2340 \\
\hline & 0.0331 & 1.3425 & 1.8924 & 60.8464 & 2.4126 \\
\hline & 0.0715 & 1.3495 & 1.9122 & 62.8422 & 2.4918 \\
\hline & 0.1166 & 1.3547 & 1.9270 & 64.7280 & 2.5665 \\
\hline & 0.2355 & 1.3611 & 1.9452 & 67.5540 & 2.6786 \\
\hline & 0.4182 & 1.3672 & 1.9627 & 69.5699 & 2.7585 \\
\hline \multirow{6}{*}{$\begin{array}{l}\text { Methanol-aque- } \\
\text { ous }\end{array}$} & 0.0000 & 1.3385 & 1.8812 & 56.3411 & 2.2340 \\
\hline & 0.0470 & 1.3411 & 1.8885 & 60.2057 & 2.3872 \\
\hline & 0.0999 & 1.3433 & 1.8947 & 61.0295 & 2.4199 \\
\hline & 0.1598 & 1.3449 & 1.8992 & 62.1703 & 2.4651 \\
\hline & 0.3074 & 1.3484 & 1.9091 & 64.0334 & 2.5390 \\
\hline & 0.5088 & 1.3502 & 1.9142 & 66.2918 & 2.6285 \\
\hline \multirow[t]{6}{*}{ Glycerol-aqueous } & 0.0000 & 1.3385 & 1.8812 & 56.3411 & 2.2340 \\
\hline & 0.0267 & 1.3530 & 1.9221 & 56.2314 & 2.2296 \\
\hline & 0.0582 & 1.3675 & 1.9636 & 57.0493 & 2.2621 \\
\hline & 0.0958 & 1.3825 & 2.0069 & 57.8507 & 2.2938 \\
\hline & 0.1981 & 1.4111 & 2.0908 & 59.1514 & 2.3454 \\
\hline & 0.3657 & 1.4318 & 2.1526 & 59.3312 & 2.3525 \\
\hline
\end{tabular}

and SLES in alcoholic-aqueous mixed solvents (ethanol, methanol, and glycerol) with different alcohol mole fractions solutions, is increase as the mole fraction of alcoholic mole fraction increase. 
Table 14 The refractive index $\left(n_{D}\right)$, the atomic polarization $\left(A_{p}\right)$, the molar refraction $\left(R_{m}\right)$ and the polarizability $(a)$ of SLES as a function of mole fraction of alcohol at $298.15 \mathrm{~K}$

\begin{tabular}{|c|c|c|c|c|c|}
\hline Solvent mixtures & $\begin{array}{l}\text { Alcohol } \\
\text { mole frac- } \\
\text { tion }\end{array}$ & $n_{D}$ & $A_{P}$ & $\begin{array}{l}R_{m} \\
\mathrm{~cm}^{3} / \mathrm{mol}\end{array}$ & $\begin{array}{l}a \\
\mathrm{~cm}^{3}\end{array}$ \\
\hline \multirow[t]{6}{*}{ Ethanol-aqueous } & 0.0000 & 1.3355 & 1.8727 & 79.1292 & 3.1376 \\
\hline & 0.0331 & 1.3421 & 1.8913 & 82.0813 & 3.2546 \\
\hline & 0.0715 & 1.3477 & 1.9071 & 84.4331 & 3.3479 \\
\hline & 0.1166 & 1.3544 & 1.9261 & 87.0435 & 3.4514 \\
\hline & 0.2355 & 1.3597 & 1.9412 & 91.1470 & 3.6141 \\
\hline & 0.4182 & 1.3666 & 1.9610 & 93.6942 & 3.7151 \\
\hline \multirow{6}{*}{$\begin{array}{l}\text { Methanol-aque- } \\
\text { ous }\end{array}$} & 0.0000 & 1.3355 & 1.8727 & 79.1292 & 3.1376 \\
\hline & 0.0470 & 1.3386 & 1.8814 & 80.2627 & 3.1825 \\
\hline & 0.0999 & 1.3422 & 1.8916 & 81.7300 & 3.2407 \\
\hline & 0.1598 & 1.3441 & 1.8969 & 83.3518 & 3.3050 \\
\hline & 0.3074 & 1.3461 & 1.9026 & 86.2182 & 3.4186 \\
\hline & 0.5088 & 1.3452 & 1.8999 & 88.3607 & 3.5036 \\
\hline \multirow[t]{6}{*}{ Glycerol-aqueous } & 0.0000 & 1.3355 & 1.8727 & 79.1292 & 3.1376 \\
\hline & 0.0267 & 1.3511 & 1.9167 & 80.5045 & 3.1921 \\
\hline & 0.0582 & 1.3636 & 1.9524 & 80.8845 & 3.2072 \\
\hline & 0.0958 & 1.3790 & 1.9967 & 80.7482 & 3.2018 \\
\hline & 0.1981 & 1.4098 & 2.0869 & 82.2605 & 3.2617 \\
\hline & 0.3657 & 1.4232 & 2.1268 & 80.3160 & 3.1846 \\
\hline
\end{tabular}

Also from the values of the measured refractive indices, of the two surfactants in alcoholic-aqueous mixed solvents (ethanol, methanol, and glycerol) with different alcohol mole fractions, the molar refraction $\left(R_{m}\right)$ can be calculated [40] using the following equation.

$R_{m}=V \varphi\left(n^{2}-1\right) /\left(n^{2}+2\right)=P_{A}+P_{E}=P_{D}+P_{T}$

where $V_{\varphi}$ is the apparent molal volume of the two surfactants in solution, $n$ is the refractive index of both SDS and SLES solution. The right hand side of Eq. (3) is equal to the total molar polarization or the distortion polarization which equal to the summation of both the electron polarization $\left(P_{E}\right)$ and the atomic polarization $\left(P_{A}\right)$. The atomic polarization $\left(P_{A}\right)$ was calculated [41] from the following equation.

$P_{A}=1.05 n^{2}$

The mean value of the molecular dipole polarizability $(\alpha$; dipole moment induced by electric field) can be calculated from the optical refractive index $(n)$ of a material containing $N$ molecules per unit volume. The refractive index is related to the polarizability $(a)$ of the molecules by Lorenz-Lorenz formula [42] as shown in the following equation.

$\left(n^{2}-1\right) /\left(n^{2}+2\right)=4 n \pi \alpha / 3$

where $n=\left(N / V_{\varphi}\right),(N)$ is the Avogadro's number and $\left(V_{\varphi}\right)$ is the apparent molal volume. From Eq. (20), the polarizabilities of both SDS and SLES in ethanol, methanol and glycerol-water with different alcohol mole fractions, were calculated. The values of the calculated molar refraction $\left(R_{m}\right)$, polarizability $(\mathrm{a})$ and the atomic polarization are recorded in Tables 13 and 14.

The molar refraction and the polarizability are directly proportional to the apparent molal volume. The molar refraction and the polarizability of both SDS and SLES in ethanol, methanol and glycerol-water, is increase as the mole fraction of ethanol, methanol and glycerol increase. This increase in the molar refraction and the polarizability of both SDS and SLES with the mole fraction of ethanol, methanol and glycerol may be related to the increase in the apparent molar volume the two surfactants with the increase in the mole fraction of ethanol, methanol and glycerol, respectively.

The molar refraction and the polarizability values of the surfactants under study were compared and it was found that molar refraction and the polarizability of the SDS surfactant is lower than that of SLES surfactant. This may be related to the presence of ether group in SLES, which may decrease the solvation (increase the association and the molar volume) of SLES than that of SDS as a result of hydrogen bond formation.

\section{Conclusion}

The CMC of both sodium dodecyl sulfate (SDS) and sodium lauryl ether sulfate (SLES) surfactants in aqueous and in alcoholic-aqueous mixed solvents (methanol, ethanol, and glycerol) with different mole fractions of alcohols, has been determined experimentally at different temperatures $(298.15,303.15,308.15$ and $313.15 \mathrm{~K})$ using the conductivity measurements. Also the CMC of both (SDS) and (SLES) was determined from surface tension measurements in water at $298.15 \mathrm{~K}$. The CMC was found to increase as the temperature and as the alcohol mole fraction increased in all solvents used. It was found good agreement between the CMC value from both conductivity and surface tension measurements. Depending on the conductivity data, the association constant $\left(K_{a}\right)$ of both (SDS) and (SLES) was also determined using Shedlowsky conductance equation. The thermodynamic parameters $\left(\Delta G^{\circ}, \Delta H^{\circ}\right.$, and $\left.\Delta S^{\circ}\right)$ of the micellization and association processes were evaluated from the temperature dependence of micellization and association constants. The results indicate that the association constant of both (SDS) and (SLES) decrease as the temperature and alcohol mole fraction increased in all solvents used. Also it was found that $\mathrm{CMC}$ and $K_{a}$ of both (SDS) and (SLES) increase in the order: methanol > ethanol $>$ glycerol. The association process was found to be spontaneous one. The density and refractive index of both 
(SDS) and (SLES) in aqueous and in alcoholic-aqueous mixed solvents (methanol, ethanol, and glycerol) with different mole fractions of alcohols, has been measured experimentally at $298.15 \mathrm{~K}$. Depending on the density data, the molar volume of the two surfactants was determined. Also depending on the refractive index data, the molar refraction and the polarizability of both SDS and SLES was calculated.

\section{Compliance with ethical standards}

Conflict of interest On behalf of all authors, the corresponding author states that there is no conflict of interest.

\section{References}

1. Desando $M$, Reeves $L$ (1986) The demicellization temperature of potassium $\mathrm{n}$-octanoate in deuterium oxide as estimated from $1 \mathrm{H}$ and $13 \mathrm{C}$ nuclear magnetic resonance spectra. Can J Chem 64(9):1817-1823

2. Elworthy P, Florence A, Macfarlane C (1968) Solubilization of surface active agents and its application in chemistry and the biological science. Chapman and Hall, London, p 117

3. Bermejo E, Zapardiel A, Pérez J, Huerta A, Hernández L (1993) Voltammetric studies of a psychotropic drug with nitro groups: determination of flunitrazepam in urine using. Talanta 40(11):1649-1656

4. Cermakova L, Rosendorfola J, Malat M (1980) Determination of critical micelle concentration of 1-carbethoxypentadecyltrimethylammonium bromide. Chem Common 45(1):210-213

5. Castedo A, Castillo J, Suárez-Filloy M, Rodrıguez J (1997) Effect of temperature on the mixed micellar tetradecyltrimethylammonium bromide-butanol system. J Colloid Interface Sci 196:148-156

6. Bakshi S (1993) Micelle formation by anionic and cationic surfactants in binary aqueous solvents. J Chem Soc, Faraday Trans 89(26):4323-4326

7. Aoudia M, Al-Haddabi B, Al-Harthi Z, Al-Rubkhi A (2010) Sodium lauryl ether sulfate micellization and water solubility enhancement towards naphthalene and pyrene: effect of the degree of ethoxylation. J Surfactants Deterg 13(1):103-111

8. Kumar G, Chauhan M, Kumar A, Chauhan S, Kumar R (2012) A study on solution behaviour of sodiumdodecyl sulphate and cetyltrimethylammonium bromide in water-alcohol mixed media. Der Chem Sin 3(3):628-635

9. Tennouga L, Mansri A, Medjahed K, Chetouani A, Warad I (2015) The micelle formation of cationic and anionic surfactants in aqueous medium: determination of $\mathrm{CMC}$ and thermodynamic parameters at different temperatures. J Mater Environ Sci 6(10):2711-2716

10. Halpern A, Colloidal system. In: A laboratory textbook. Prentice Hall, Upper Saddle River, pp 469-477

11. Motin M, Mia M, Reza K, Islam A, Yousuf M, Salam M (2012) Effect of sodium dodecyl sulfate on volumetric properties of methanol ethanol n-propanol and iso-propanol at (298.15-323.15) K. Dhaka Univ J Sci 60(1):129-136

12. Shirzad S, Sadeghi R (2014) Micellization properties and related thermodynamic parameters of aqueous sodium dodecyl sulfate and sodium dodecyl sulfonate solutions in the presence of 1-propanol. Fluid Phase Equilib 377:1-8
13. Kolesnikova E, Glukhareva N (2009) The influence of an electrolyte on micelle formation in aqueous solutions of sodium monoalkyl sulfosuccinates. Russ J Phys Chem A 83(12):2119-2121

14. Kumar S, Parikh K (2012) Influence of temperature and salt on association and thermodynamic parameters of micellization of a cationic gemini surfactant. J Appl Solut Chem Model 1(1):65-73

15. El-Dossoki F (2013) Micellization thermodynamics of some imidazolium ionic liquids in aqueous solutions: conductometric study. J Solut Chem 42(1):125-135

16. Bhattarai A, Shrivastav G, Adhikari C (2014) Study of critical micelle concentration of cetyltrimethylammonium bromide (CTAB) in pure water in presence and absence of magnesium sulphate and sodium sulphate by measuring conductivity meter. Bibechana 11(1)

17. Esan O, Olubunmi O, Olumuyiwa A, Olarenwaju O (2015) Effects of temperature and tetramethylammonium bromide salt on the micellization of cetyltrimethylammonium bromide in aqueous medium: a conductometric studies. Int J Thermodyn 18(4):246-252

18. Corradini F, Franchini G, Marchetti A, Tagliazucchi M, Tassi L, Tosi G (1993) Conductivity of tetraphenylphosphonium bromide in 2-methoxyethanol-water. J Chem Soc, Faraday Trans 89(16):3043-3047

19. Haq Z, Rehman N, Ali F, Khan N, Ullah H (2017) Physico-chemical properties of cationic surfactant cetyltrimethylammonium bromide in the presence of electrolyte. J Mater Environ Sci 8(3):1029-1038

20. Bhattarai A, Adhikari C, Shrivastav G (2014) Density and partial molar volume of cetyltrimethylammonium bromide in the presence and absence of $\mathrm{Na}_{2} \mathrm{SO}_{4}$ and $\mathrm{MgSO}_{4}$. Int J Eng Tech Res 11:74-76

21. El-Dossoki F (2016) Volumetric thermodynamic properties of aqueous binary mixtures of some alkanols at different temperatures. Int Res J Pure Appl Chem 10(3):1-18

22. El-Dossoki F, El-hasan E, Abdelrhman E (2016) Solvation of parachloro meta xylenol (PCMX) in alcohols-aqueous solutions at 293. 15 K. Int J Adv Res Chem Sci 3(9):19-28

23. El-Dossoki F (2018) phase diagrams, molal volumes and polarizabilities of (lysine, methionine amino acids-alcohol-water) tricomponent systems. Int Res J Pure Appl Chem 16(2):1-11

24. El-Dossoki F (2015) Volumetric and solvation properties of glycyl-glycine and glycyl-L-leucine in aqueous acetate solutions. J Solut Chem 44(2):264-279

25. Hosny N, Badr M, El-Dossoki F (2018) Doped poly(m-phenylenediamine-co-aniline) (P(mPD-co-ANI)): synthesis, characterization, physical properties, and precursor for $\mathrm{CuO}$ nanoparticles. Polym Plast Technol Eng 57(14):1485-1495

26. El-Dossoki F (2007) Refractive index and density measurements for selected binary protic-protic, aprotic-aprotic, and aproticprotic systems at temperatures from $298.15 \mathrm{~K}$ to $308.15 \mathrm{~K}$. J Chin Chem Soc 54(1):1129-1137

27. El-Dossoki F, Gommaa E (2005) Excess refractive index, polarizability, polarization and the molar volume of some mixed solvents. J Indian Chem Soc 82(3):219-224

28. Lide D (1995) CRC handbook of chemistry and physics, 76th edn. CRC Press, Boca Raton

29. Tyowua A, Yiase S, Wuanna R (2012) Manipulation of concentration-conductivity data of sodium dodecyl sulphate and sodium dodecylbenzene sulphonate in $\mathrm{KCl}$ solution in relation to micellisation parameters. Chem Sci J 3:1-9

30. Onsager $L$ (1933) Theories of concentrated electrolytes. J Chem Rev 13(1):73-89

31. Shedlovsky $T$ (1938) The computation of ionization constants and limiting conductance values from conductivity measurements. J Frankl Inst 225(6):739-743 
32. Covington A, Dickinsoa T (1973) Physical chemistry of organic solvent systems. Plenum Press, London

33. El-Hammamy N, El-Araby H (2016) Electrical conductivity and thermodynamic studies on sodium diethyldithiocarbamate in methanol at different temperatures. Int J Electrochem Sci 11(10):8709-8721

34. Walden P (1920) Über Den ZusammenhangZwischen Dem Grenzleitvermögen $\lambda_{\infty}$ Der BinärenElektrolytelnNichtwässerigenLösungsmitteln Und Der Viskosität $\eta_{\infty}$ Der Letzteren $\lambda \infty$. $\eta \infty=$ konst. Zeitschrift für Anorg und Allg Chemie 113(1):85-97

35. Wadi R, Kakkar V, Kakkar R (2000) Partial molar volumes and viscosities of some monovalent ions in ethanolamine and waterethanolamine mixtures at $298.15 \mathrm{~K}$. Indian J Chem Sect A Inorg Phys Theor Anal Chem 39(6):598-602

36. Millero F (1968) Apparent molal expansibilities of some divalent chlorides in aqueous solution at 25. deg. J Phys Chem 72(13):4589-4593

37. King $E$ (1969) Volume changes for ionization of formic, acetic, and butyric acids and the glycinium ion in aqueous solution at 25.deg. J Phys Chem 73(5):1220-1232

38. Millero J, Surdo A, Shin C (1978) The apparent molal volumes and adiabatic compressibilities of aqueous amino acids at 25 C. J Phys Chem 82:784-792
39. Gopal R, Siddiqi M (1969) Study of ion-solvent interaction of some tetraalkylammonium and common ions in N-methylacetamide from apparent molal volume data. J Phys Chem 73(10):3390-3394

40. El-Harakany A, El-Dessouky M, Taha A, Bassiony A (2002) Solubilities and thermodynamic functions of transfer of substituted benzoic acids and aliphatic amine derivatives from water to water-sulpholane mixtures at different temperatures. Egypt J Chem 45(1):1-32

41. Mognaschi E, Laboranti L (1996) Association of pure polar liquids: dielectric properties of docosanoic acid. J Chem Soc, Faraday Trans 92(18):3367-3369

42. Hasted J (1973) Aqueous dielectrics. Chapman and Hall, New Yourk

Publisher's Note Springer Nature remains neutral with regard to jurisdictional claims in published maps and institutional affiliations. 